\title{
Natural Mexican Zeolite Modified with Iron to Remove Arsenic Ions from Water Sources ${ }^{\dagger}$
}

\author{
Maritza E. Garay-Rodríguez 1, Mirella Gutiérrez-Arzaluz 2,*, Jesús Mejía-Saavedra 3, \\ Leticia Carrizales-Yánez ${ }^{3}$, Violeta Mugica-Álvarez ${ }^{2}$ and Miguel Torres-Rodríguez ${ }^{2}$ \\ 1 Posgrado en Ciencias e Ingeniería, Universidad Autónoma Metropolitana-Azcapotzalco, 02200 Mexico City, \\ Mexico; ing.amb_megr@hotmail.com \\ 2 Departamento de Ciencias Básicas, Universidad Autónoma Metropolitana-Azcapotzalco, 02200 Mexico City, \\ Mexico; vma@azc.uam.mx (V.M-A.); trm@azc.uam.mx (T.R-M.) \\ 3 Centro de Investigación Aplicada en Ambiente y Salud, CIACyT-Facultad de Medicina, U.A.S.L.P., \\ San Luis Potosí, S.L.P. 78210, Mexico; jjesus@uaslp.mx (J.M-S.); letcay@uaslp.mx (L.C-Y.) \\ * Correspondence: gam@azc.uam.mx; Tel.:+52-(1)-5553189570 \\ + Presented at Environment, Green Technology and Engineering International Conference (EGTEIC 2018), \\ Caceres, Spain, 18-20 June 2018.
}

Published: 23 October 2018

\begin{abstract}
In this work the elimination of arsenic ions (V) in water was investigated by adsorption with Mexican natural zeolite (clinoptilolite type) conditioned with iron, the zeolite originating in the state of Oaxaca in Mexico used as an adsorbent medium was placed in a bed zeolite fixed column system of downward and upward flow to retain arsenic ions at $\mathrm{pH} 7$ and 5 . The zeolite was characterized by XRD, SEM/EDS and FTIR before and after the arsenic adsorption tests, the results showed that the methods of modification used are suitable for the superficial modification of the natural zeolite since it does not modify its structure. The results showed that with an initial concentration of As of $1 \mathrm{ppm}$, at a $\mathrm{pH}$ of 7 , at $25^{\circ} \mathrm{C}$, an elimination of $99.23 \%$ was obtained, with a capacity of $0.09 \mathrm{mg}_{\mathrm{As}} \cdot \mathrm{g}^{-1}$ zeolite.
\end{abstract}

Keywords: adsorption; ion arsenic; natural zeolite

\section{Introduction}

The Arsenic is an element present in the earth's crust and dispersed in the environment through natural processes and some anthropic activities. It is released into the environment naturally through the weathering and erosion of mineral sulfides, some activities such as mining, the use of wood protectors potentially increase its concentration in air, water and soil. In aqueous phase is found in inorganic form, in the form of arsenate and arsenite mainly, the pollution of groundwater by salts of this element originates what is known as endemic regional hydroarsenicism. The International Agency for Research on Cancer (IARC) [1] categorizes the inorganic As within group I, as a substance with proven carcinogenic action for humans. The presence of As has been found in groundwater in several countries such as Argentina, Mexico, Bangladesh, Canada and the United States. Regarding the concentration of arsenic in drinking water, the World Health Organization (WHO) and the Environmental Protection Agency (EPA) establish maximum concentrations of $10 \mu \mathrm{g} \cdot \mathrm{L}^{-1}$. In Mexico, in some states such as Hidalgo [2], Morelos and Michoacán concentrations of arsenic have been found in bodies of water at around $1000 \mu \mathrm{g} \cdot \mathrm{L}^{-1}$, a concentration that is well above what is allowed by Mexican regulations with the NOM-127-SSA1-1994 which establishes a limit of $25 \mu \mathrm{g} \cdot \mathrm{L}^{-1}$. Given this problem in Mexico, the use of a Mexican natural zeolite (clinoptilolite type) modified superficially with iron, originally from the district of Etla in the region of the central valleys of Oaxaca, is proposed as an adsorbent medium for the removal of arsenic. 


\section{Experimental}

The natural zeolite used in this study was collected from Mexican tuff in a deposit of the district of Etla (latitude 17.232951, longitude -96.810989) in the region of the central valleys in the state of Oaxaca. The samples were milled and sieved to 16 mesh size, washed with deionized water to remove impurities and dried at $100{ }^{\circ} \mathrm{C}$. The previously washed natural zeolite was subjected to an ion exchange with $100 \mathrm{~mL}$ of $2 \mathrm{M} \mathrm{NaCl}$ solution using $10 \mathrm{~g}$ of natural zeolite at room temperature for 24 $\mathrm{h}$, then washed and dried at $100{ }^{\circ} \mathrm{C}$ to obtain the sodium zeolite. Then the sodium zeolite was conditioned with $\mathrm{Fe}\left(\mathrm{NO}_{3}\right)_{3} \cdot 9 \mathrm{H}_{2} \mathrm{O}$ solution $0.5 \mathrm{M}$, and was deposited on the zeolite by the precipitation-impregnation method using as $\mathrm{NH}_{4} \mathrm{OH}$ precipitant agent, subsequently dried at $100^{\circ} \mathrm{C}$ for $24 \mathrm{~h}$ and finally washed with deionized water and dry again at $100^{\circ} \mathrm{C}$. Table 1 show the adsorbent materials used in the removal of arsenic ions $(\mathrm{V})$.

Table 1. Adsorbents materials.

\begin{tabular}{cc}
\hline Sample & Description \\
\hline ZN & Natural zeolite \\
ZN-Na & Zeolite sodium \\
ZN-Fe & Zeolite with Fe \\
\hline
\end{tabular}

The materials in Table 1 were characterized, before and after the adsorption process by: X-ray Diffraction (XRD) in a Philip diffractometer, $X^{\prime}$ pert model, Scanning Electron Microscopy (SEM/EDS) in a Supra 55VP microscope, Carl Zeiss. Fourier Transform Infrared Spectroscopy (FTIR), in a Varian model spectrometer Excalibur 3600. To determine the arsenic removal capacity of water contaminated with the adsorbent materials, two upflow and downflow column systems were used with a fixed bed of $10 \mathrm{~g}$ of adsorbent material and $100 \mathrm{~mL}$ of $\mathrm{As}^{+5}$ solution at $\mathrm{pH} 7$ and modify the $\mathrm{pH}$ with $\mathrm{HCl}$ to 5 , with a contact time of $24 \mathrm{~h}$ for the downflow column and with continuous flow 0.3 $\mathrm{ml} / \mathrm{min}$ for the upflow column. All tests were performed with concentration of $1 \mathrm{ppm}$, room temperature and an output flow rate of $0.3 \mathrm{~mL} / \mathrm{min}$. The determination of arsenic was carried out by analysis of atomic absorption of the water samples treated in the Center for Applied Research in Environment and Health (CIAAS) within the Coordination for the Innovation and Application of Science and Technology (CIACYT) in the state of San Luis Potosí.

\section{Results and Discussion}

Figure 1a shows the XRD results of the natural and conditioned zeolites, the diffractogram of the natural zeolite corresponds to the diffraction peaks of the clinoptilolite type zeolite according to that reported by Mansouri [3] and correspond with the same peaks of the zeolite conditioned with iron so it is stated that the structure of the zeolite was not altered after the conditioning treatments. The Figure $1 \mathrm{~b}$ shows the results of FTIR of natural zeolite and that conditioned with Fe, where the characteristic bands of a zeolite are observed. The samples modified with iron, also present the bands corresponding to the presence of water and the presence of $\mathrm{Fe}_{2} \mathrm{O}_{3}$ [4].

Table 2 shows the results of the SEM/EDS analysis, for the washed natural zeolite, the sodium zeolite and the zeolite conditioned with $\mathrm{Fe}$, after the ion exchange with $\mathrm{Na}$, the percentage increase of the Na cation is observed. The zeolite conditioned with Fe increased its percentage 13 times more (bold letters) with respect to the content of this metal in the natural zeolite. 


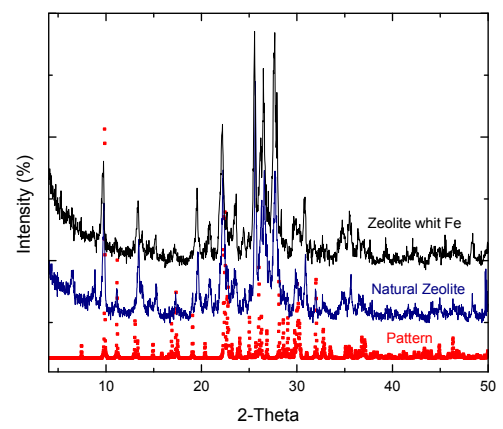

(a)

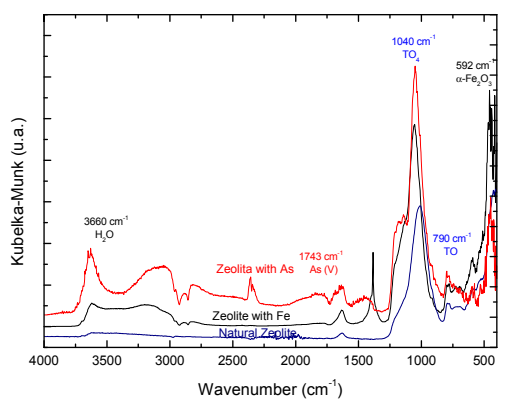

(b)

Figure 1. (a) XRD diffractograms of the natural and conditioned zeolite, (b) FTIR spectrums of the natural and conditioned zeolite.

Table 2. SEM/EDS analysis of natural and conditioned zeolites.

\begin{tabular}{ccccc}
\hline \multirow{2}{*}{ Element } & \multicolumn{4}{c}{ wt \% } \\
\cline { 2 - 5 } ZN K & 26.98 & 34.31 & 25.79 & 28.1 \\
O K & 56.40 & 50.38 & 44.81 & 53.78 \\
Al K & 5.91 & 5.64 & 4.72 & 4.57 \\
Na K & 1.55 & 5.22 & 3.67 & 0.9 \\
Mg K & 0.36 & 0.24 & 0 & 0.09 \\
K K & 3.83 & 1.68 & 1.64 & 2.68 \\
Fe K & 1.25 & 1.85 & 16.34 & 7.24 \\
C K & 3.40 & 0.68 & 3.03 & 2.3 \\
Ca K & 0.32 & 0 & 0 & 0 \\
As L & 0 & 0 & 0 & 0.36 \\
Total & 100 & 100 & 100 & 100 \\
\hline
\end{tabular}

The results of the removal of As from contaminated water are presented in Table 3, these data indicate that natural clinoptilolite type zeolite is not feasible to remove $\mathrm{As}(\mathrm{V})$ ions from water. The conditioning of the natural zeolite with Fe greatly favoured the removal of the As ions in both column systems (downflow and upflow) since an average adsorption capacity of $0.09 \mathrm{mg}_{\mathrm{As}} \cdot \mathrm{g}^{-1}$ zeolite was obtained for downflow and $0.35 \mathrm{mg}_{\mathrm{As}} \cdot \mathrm{g}^{-1}$ zeolite for upflow, at temperature environment with neutral $\mathrm{pH}$ and with a particle size of $1.18 \mathrm{~mm}$. In both studies equilibrium is not reached, these values are a three times larger environment in the upflow column since it is a greater volume treated of water contaminated with arsenate ion. The removal is slightly favoured when the $\mathrm{pH}$ of the solution is modified to 5 in both systems, however it can be suggested that the two column systems are appropriate to eliminate the arsenic ions $(\mathrm{V})$.

The removal of arsenic from a real sample obtained from the state of Guanajuato with an initial content of $0.020 \mathrm{mg} \cdot \mathrm{L}^{-1}$ of As, presented optimal results with a percentage removal of $100 \%$ using the downflow column with the conditioned zeolite and $\mathrm{pH}$ of 7.5 and the $600 \mathrm{~mL}$ of natural water were treated. 
Table 3. Adsorption of ions $\mathrm{As}(\mathrm{V})$ in column system with natural and modified zeolite.

\begin{tabular}{|c|c|c|c|c|c|c|}
\hline $\begin{array}{c}\text { Adsorbent } \\
\text { Material }\end{array}$ & $\mathrm{pH}$ & $\begin{array}{c}\text { Initial As } \\
\left(\mathrm{mg} \cdot \mathrm{L}^{-1}\right)\end{array}$ & $\begin{array}{c}\text { Removed As } \\
\left(\mathrm{mg} \cdot \mathrm{L}^{-1}\right)\end{array}$ & $\begin{array}{c}\text { Volume } \\
\text { Treated (mL) }\end{array}$ & $\begin{array}{c}\text { Removal } \\
(\%)\end{array}$ & 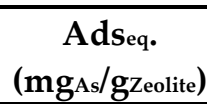 \\
\hline & \multicolumn{6}{|c|}{ Downflow column } \\
\hline ZN & 7 & 1 & 1 & 1000 & 0 & 0 \\
\hline $\mathrm{ZN}-\mathrm{Fe}$ & 7 & 1 & 9.92 & 1000 & 99.23 & 0.099 \\
\hline $\mathrm{ZN}-\mathrm{Fe}$ & 5 & 1 & 9.99 & 1000 & 99.51 & 0.109 \\
\hline & \multicolumn{6}{|c|}{ Upflow column } \\
\hline ZN & 7 & 1 & 1 & 3600 & 0 & 0 \\
\hline $\mathrm{ZN}-\mathrm{Fe}$ & 7 & 1 & 0.96 & 3600 & 96.12 & 0.349 \\
\hline ZN-Fe & 5 & 1 & 0.98 & 3680 & 98.25 & 0.357 \\
\hline
\end{tabular}

\section{Conclusions}

It was possible to remove As from contaminated water efficiently, with an initial concentration of $1 \mathrm{mg} \cdot \mathrm{L}^{-1}$, in the two column systems, using as adsorbent material a natural Mexican zeolite, conditioned with $\mathrm{Fe}$, in this study it was found that iron incorporation favors the removal of As since the natural zeolite is not able to retain the As. With these results it is affirmed that the conditioned natural zeolite is apt to remove As (V) of water in the two column systems and at the two studied $\mathrm{pH}$. However, the best results were obtained in the downflow column with $99.5 \%$ elimination and at $\mathrm{pH}$ 5. The results of XRD, SEM/EDS and FTIR have shown that the conditioning methods allowed to generate a material with adsorbent properties ideal for the removal of arsenic from contaminated water and allowed to corroborate the presence of As adsorbed in the material. This research could help the development of a prototype that combines the advantages of a conventional filter with those of a natural adsorbent medium conditioned with $\mathrm{Fe}$, providing a continuous treatment, of low cost and relatively easy to operate, for its implementation in marginalized areas of Mexico.

Author Contributions: M.G-A. and M.T-R. conceived of and designed the experiments and analyzed the data, M.G-A. performed the experiments, J.M-S. and L.C-Y. designed the analyzes by AAS and V.M-A wrote the paper.

Acknowledgments: Garay Rodríguez thanks the CONACyT scholarship and the co-authors thank the Divisional Electronic Microscopy Laboratory of the UAM-A.

Conflicts of Interest: The authors declare no conflict of interest.

\section{References}

1. IARC Monographs on the evaluation of de carcinogenic risk of chemical to humans. Chemicals, Industrial Processes and Industries Associated with Cancer in Humans. IARC Monogr. 1982, 1-29, 1-292.

2. Armienta, M.A.; Villaseñor, G.; Rodriguez, R.; Ongley, L.K.; Mango, H. The role of arsenic-bearing rocks in groundwater pollution at Zimapán Valley, México. Environ. Geol. 2001, 40, 571-581. doi:10.1007/s002540000

3. Mansouri, N.; Rikhtegar, N.; Panahi, H.A.; Atabi, F.; Shahraki, B.K. Porosity, characterization and structural properties of natural zeolite-clinoptilolite as a sorbent. Environ. Prot. Eng. 2013, 39, 139-152. doi:10.5277/EPE130111

4. Štajdohar, J.; Ristic', M.; Music, S. The effect of experimental conditions on the microstructure of hematite particles precipitated by the forced hydrolysis of $\mathrm{FeCl}_{3}$ solutions. Mol. Struct. 2013, 1044, 290-298. doi:10.1016/j.molstruc.2012.09.073.

(C) 2018 by the authors. Licensee MDPI, Basel, Switzerland. This article is an open access article distributed under the terms and conditions of the Creative Commons Attribution (CC BY) license (http://creativecommons.org/licenses/by/4.0/). 